August 14, 1928. Slight fundus reflex is present, but fundus details are not visible.

August 15, 1927. There is no conjunctival injection or proptosis. Although he cannot see, he is feeling well and wishes to be discharged. Having read Dr. Shroff's article in the February number of Brit. Jl. of Ophthal., I am tempted to put on record the above case which is like the one described by him. The points of difference being the long duration of time since the accident happened, till the time when he applied for help, and the consequent iritis with seclusion and occlusion of the pupil. It is remarkable that with a thorn as long as one inch and a quarter, lying in the orbit right under the lid, which is always in motion, and with the iritis that ensued, the patient, who was a powerful agricultural labourer, did not feel himself out of sorts and only applied for help when, four months after the accident, chemosis set in. Evidently the tenonitis which was late in appearing had compelled him to seek relief and this was brought on by some sort of interference with the eye, although he denied it.

Repeated letters to him since February have not elicited any response from him. But I shall report it if I hear of any further change in the future.

\title{
REMARKS REGARDING THE DISCUSSION UPON THE AETIOLOGY AND TREATMENT OF HYPOPYON ULCER
}

BY

G. Herbert Burnham, M.D.Tor., F.R.C.S.Edin.

EMERITUS PROFESSOR OF OPHTHALMOLOGY AT UNIVERSITY OF TORONTO

AfTER reading the discussion on the treatment of hypopyon ulcer in the Transactions of the Ophthalmological Society of The United Kingdom, 192 $\mathrm{f}$, I beg to add to the list of remedies which have been brought forward, one which has not been in any respect alluded to; I refer to "The Combined Treatment"** which I have used in this disease for many years with great satisfaction.

When an ulcer of the cornea is so far advanced as to have hypopyon associated with it, then it is of course of a type that has always as a complication iritis more or less severe. "The Combined 'Treatment" consists of the hypodermic injection of pilocarpine and the internal administration of mercury and the

* "The Combined Treatment" of Diseases of the Eye, by G. Herbert Burnham, M.D.Tor,, F.R.C.S.Edin. Publisher, H. K. Lewis, 136, Gower Street, London, W.C. 1906. 
iodide and bromide of soda. With this disease there is always present a conjunctivitis of varying degrees of severity.

In a case coming to me presenting all the appearances and symptoms of hypopyon ulcer with iritis, my mode of procedure is as follows :- I commence by freely dropping into the eye a solution of argyrol or neosilvol gr. $\mathrm{xx}$ to one drachm; then a few drops of atropine gr. $\frac{1}{2}$ to a drachm, each once daily, and at the same time begin the use of "'The Combined Treatment."

The first of these remedies is to check the conjunctivitis and the second to act upon the pupil ; but being of little intrinsic value they are soon set aside. My chief, my sole reliance I may say, is placed upon "The Combined Treatment." This latter is inaugurated by giving a series of twenty hypodermic injections of pilocarpine, one every day. The strength of each injection is to begin with gr. 1/12 and the dose can be gradually increased, if borne, to gr. $\frac{1}{4}$, and in some cases even to gr. $\frac{1}{3}$.

During the series the mercury is given twice daily one half hour after eating, and the iodide and bromide of soda twice daily one hour after eating. However, between series the medicines are given thrice daily. Very quickly indeed the eye feels easier, and locally it will be seen that the edges of the ulcer begin to be more sharply defined, and the surrounding cornea clear and brighter, and this progress is continuous, so that at the end of the series the ulcer is quite noticeably healthier and the pupil partially or fully dilated according to the severity of the case.

In four to six weeks a series of ten injections of pilocarpine is again practised and this is kept up at these intervals till the cornea becomes clear with good vision, in other words, practically a normal eye. I have always found this form of treatment so superior in every way to any other usually made use of, that it is now my only mode of treatment in these cases.

When I meet with an hypopyon ulcer, unless it be very advanced, I fully expect to be able to verify my prognosis of a complete recovery. If, however, it be too diseased to be able to anticipate a clear cornea, then I say that the vision will be affected owing to a nebula or leucoma, but that the contour of the eyeball will remain unaffected, that is, that no unsightly staphyloma will necessitate the removal of the eye.

Thus it will naturally be gathered from these remarks that no operative procedures, whatsoever, are mentioned, and that the treatment advocated so recommends itself to me and the results of long experience in its employment are such, that I feel that I am justified in saying that in my opinion it occcupies in regard to its power of healing in this disease, an almost unique position and one in every way better than any yet brought to my attention.

This may seem an enthusiastic statement, but I feel assured that 
if this form of treatment be faithfully carried out as I have elsewhere given full directions, it will be admitted that I have not overstated or exaggerated its great influence for good in this affection.

\title{
A CASE OF BRAWNY TENONITIS
}

\section{BY}

\author{
R. R. JAMES \\ LONDON
}

A woman aged 48 years attended my out-patient department at St. George's Hospital on April 14, 1928. Her eyes presented the striking appearance of what was called brawny scleritis by the late Sydney Stephenson. She gave the following history.

In 1889 she had had a tenotomy of the internal rectus of the left eye performed at Guy's Hospital by Mr. Higgens. The right eye had been inflamed for about four years and she had seen several ophthalmic surgeons about it; recently the left eye had begun to be affected in a similar manner.

She was wearing +4.0 D. sph. glasses for distance and +5.5 D. sph. for near work. 'The left eye was divergent; with her glasses the right eye obtained an acuity of $6 / 9$; the left eye was found to be amblyopic and vision was reduced to counting fingers.

The illustration by Theodore Hamblin, Ltd., shows the state of affairs better than any verbal description. The peculiar salmoncoloured tint, together with the semi-solid looking chemosis of the conjunctiva has only to be seen once to be remembered. In the left eye it was instructive to see the process in its earliest stages. This appears as a uniform redness at the equator of the eye in its upper part, the swelling is slight, and no appearance of chemosis is visible; the front parts of the eye are normal. The chemotic area pits slightly on pressure. The Wassermann reaction is negative.

In this case the right optic disc showed an extensive congenital fibrous film.

A similar case was shown at a meeting of the Ophthalmological Section of the Royal Society of Medicine in the year 1913 under the title, "Brawny Scleritis," by Mr. Sydney Stephenson. It was published, with a coloured illustration, in the Proceedings, Vol. VII, p. 1.

In the discussion that followed, Mr. Treacher Collins expressed the opinion that the condition was really one of tenonitis and not of scleritis. With this view I am in entire agreement; I see no evidence in this case of any involvement of the sclera, and the condition of the left eye, in my opinion, supports the latter view. 